\title{
A Educação Química em discurso: uma análise a partir da revista Química Nova na Escola (1995-2014)
}

\section{Chemical Education in discourse: an analysis from Química Nova} na Escola (1995-2014)

\section{Bruno S. Pastoriza e José Claudio Del Pino}

Resumo: Em função da recente comemoração dos 20 anos da revista Química Nova na Escola (QNEsc), este texto visa compartilhar com a comunidade da Educação Química os resultados de um estudo de doutorado que analisou o discurso produzido nessa área a partir das investigações publicadas na QNEsc de 1995 a 2014. Utilizando bases teóricas e metodológicas da Análise de Discurso na pesquisa, desenvolvidas por meio de Análise Temática dos documentos, o artigo aponta a emergência de um enunciado produzido e produtor de um discurso da Educação Química cuja centralidade das ações, dos planejamentos e operações estaria em um sujeito aluno tomado, sistematicamente, a partir de seu nível cognitivo. Compartilhar essa pesquisa com a comunidade da Educação Química visa a trazer uma análise distinta das usuais, em função de seu campo teórico, apresentar outros modos de compreender o próprio discurso objeto de estudo e, assim, potencializar diferentes formas de operar, atuar e produzir nessa área.

Palavras Chave: Educação Química, Análise de Discurso, Enunciado.

\begin{abstract}
From the celebration of 20th year of Química Nova na Escola (QNEsc), results of a doctoral analysis of the discourse produced in the field of Chemical Education are presented. The study was developed on QNEsc publications from 1995 to 2014. Theoretical and methodological bases of Discourse Analysis are assigned by the Thematic Analysis and the results are presented as the production of a statement that emphasizes the necessity of a student subject and his cognitive level. The study highlights a different way to comprehend the Chemical Education field by a specific theoretical background. The knowledge of this discussion about the Chemical Education discourse is presented as an outcome that provides more control over school chemistry education itself and its productions.
\end{abstract}

Keywords: Chemical Education, Discourse Analysis, Statement.

\footnotetext{
Bruno dos Santos Pastoriza (bspastoriza@ ufpel.edu.br) é doutor e mestre em Educação em Ciências e licenciado em Química pela Universidade Federal do Rio Grande do Sul (UFRGS), Professor Adjunto da Universidade Federal de Pelotas (UFPel) e coordenador do Laboratório de Ensino de Química ((LABEQ-UFPel). Pelotas, RS - BR. José Claudio Del Pino (delpinojc@yahoo.com.br), é pós-doutor em Ensino de Ciências pela Universidade de Aveiro, doutor em Engenharia de Biomassa e mestre em Bioquímica pela UFRGS e licenciado em química Pontifícia Universidade Católica do Rio Grande do Sul (PUCRS) e Professor da Universidade Integrada Vale do Taquari de Ensino Superior (UNIVATES), colaborador da Área de Educação Química da Universidade Federal do Rio Grande do Sul (UFRGS), pesquisador 1D CNPq, ex-editor da Revista Química Nova na Escola e consultor ad hoc de outras instituições. Porto Alegre, RS - BR. Recebido em 24/08/2016, aceito em 09/01/2017
}

A seção "Cadernos de Pesquisa" é um espaço dedicado exclusivamente para artigos inéditos (empíricos, de revisão ou teóricos) que apresentem profundidade teórico-metodológica, gerem conhecimentos novos para a área e contribuições para o avanço da pesquisa em Ensino de Química. 
Em 2015, a Revista Química Nova na Escola (QNEsc) completou seus 20 anos de publicação. Mais do que isso, essa data marcou 20 anos de constituição, desenvolvimento e legitimação de uma comunidade preocupada com os processos de ensino, aprendizagem, teorização, problematização e pesquisa dos modos de se produzir conhecimentos e saberes escolares, pedagógicos, técnicos, docentes, dentre tantos outros correlatos ao universo do educar em Química. Como forma de celebração, a QNEsc publicou, em dezembro de 2015, uma edição especial comemorativa, na qual se fazem presentes tanto análises gerais acerca das produções da revista quanto proposições e direcionamentos para avanços da área em níveis nacional e internacional (Revista Química Nova na Escola, 2015).

Centrada na divulgação de pesquisas no campo da Educação Química, com vistas ao aprimoramento das práticas de sala de aula e da formação de professores e professoras da área da Química (Revista Química Nova na Escola, 2013; 1995), a QNEsc é publicada ininterruptamente desde 1995. Ela foi idealizada inicialmente em 1994, no VII Encontro Nacional de Ensino de Química (ENEQ), momento em que a conjuntura da época colocava como urgente a necessidade de se pensar a respeito das práticas da sala de aula de Química. A partir de seu foco, em sua existência, a revista já publicou, além dos números usuais, uma série de oito Cadernos Temáticos e um conjunto de vídeos (que totalizam cerca de quatro horas de duração) com a intenção de serem distribuídos massivamente às escolas da Educação Básica para qualificar a Química escolar.

Em sua constituição, a QNEsc consubstancia um ambiente que tanto busca uma identidade para a Química trabalhada na escola quanto propõe um modo de falar acerca dessa escola, da formação de professores, de metodologias, de conceitos químicos, de ensaios de laboratórios, de adaptações, transposições, recontextualizações, entre outros componentes da prática da Química escolar. Isso a diferencia dos antigos projetos de educação científica, que, conforme alguns estudos (Krasilchik, 2000), tinham por base qualificar as ciências na escola e aproximá-las mais às noções de redescoberta e de cientificidade. Aliado a isso, a QNEsc também se distingue de outras revistas científicas já existentes à época de sua inauguração, uma vez que os focos destas não estavam especificamente na formação de professores em nível básico no Brasil (Bejarano e Carvalho, 2000). Conforme apontam Santos e Porto (2013), o perfil organizado pela QNEsc, destinado à ação de formação de professores na Educação Básica, trouxe um diferencial às publicações periódicas e contribuiu significativamente com a discussão do conhecimento químico e seus processos de ensino e aprendizagem. Tal importância é notada, segundo os mesmos autores, quando se percebe que a QNEsc também contribuiu como inspiração à organização de outras revistas no campo da Educação Química fora do Brasil e, ainda, de outros campos, como do Ensino de Física.

Reiterando esse cenário de destaque da QNEsc na ação e problematização da Química trabalhada no espaço da escola,
Schnetzler (2002, p. 20) aponta que, embora uma revista como a Química Nova já apresentasse sua seção de "Educação" desde 1980, já em seus primeiros sete anos de existência a QNEsc “(...) publicou e divulgou 177 artigos, contrastando com 173 publicados na seção de educação da revista Química Nova durante 24 anos".

Desse modo, a QNEsc emerge como um acontecimento importante na constituição e legitimação da área da Educação Química, cujo foco e ênfase a destacam entre as outras revistas existentes no campo e a permitem ser um dos marcos das discussões brasileiras no tocante ao ensino da Química no contexto escolarizado. Em seu percurso de consolidação e ampliação, é necessário marcar, ainda, que, embora grande parte dos estudos remeta à Educação Básica, é crescente nessa revista, nos últimos anos, a publicação de pesquisas focadas no Ensino Superior da Química (Castro et al., 2015; Santos et al., 2014; Braibante e Wollmann, 2012).

Com essa multiplicidade de propostas voltadas à produção de saberes e conhecimentos no campo da Química e, particularmente, da Química na escola, a QNEsc foi ganhando destaque no campo da Educação Química, de modo que, em geral, autores que com ela contribuem reconhecem:

(...) a troca de idéias entre químicos e educadores químicos é de fundamental importância para a produção de novas compreensões do que é básico e importante a ser ensinado no campo da Química para as novas gerações (...) [e, ainda,] a atenção e seriedade que dão os químicos às questões educacionais e os educadores químicos às questões da Química nos deixa [educadores químicos] convictos que aquilo que publicamos é a melhor compreensão sobre determinado assunto ou tema, em cada uma das seções, e que aquilo é adequado sob o ponto de vista da Química e da Educação em Química (Revista Química Nova na Escola, 2008, p. 1).

Destacada por essas características, a revista ainda se sobressai por sua atuação política e inserção nas questões correlatas à educação nacional. Basicamente, as políticas educacionais, nacionais, regionais e, inclusive, internacionais, para o campo das ciências e, em especial, da Química, tiveram como articuladores, em certo ponto, algum autor da revista e, também, em vários de seus editoriais, ela marca sua presença política ao colocar questões importantes à educação, como financiamento, currículo, propostas governamentais, dentre outros aspectos.

É necessário assinalar que a emergência da área da Educação Química não se dá unicamente a partir da constituição da QNEsc. Conforme apontam Santos e Porto (2013), Nardi (2007), Cachapuz et al. (2005), Mortimer (2004), dentre outros, percebemos a proposição e desenvolvimento da área aliados ao movimento de intensificação de encontros, eventos e pesquisas 
nesse campo. Dessa forma, a QNEsc se configura como um modo diferenciado, identitário, abrangente e disperso de uma revista atuante e mobilizadora de ações e processos no campo da Educação Química. Sua presença no cenário educacional desde 1995, sua publicação contínua, os diferentes materiais produzidos, o espaço de participação de químicos e educadores químicos e sua atuação política fazem notar que a revista apresenta uma força bem consolidada e uma grande abrangência em nível nacional e internacional (Ramos et al., 2015; Cachapuz, 2015; Caamaño; 2015; Santos e Porto, 2013; Mortimer, 2004).

Esse conjunto amplo de publicações, colaboradores e outros modos de produções, torna a revista Química Nova na Escola um material potente de análise da Educação Química na atualidade, particularmente a brasileira, bem como um instrumento de produção de saberes em Educação Química que merece ser, cada vez mais, divulgado.

No conjunto dessas comemorações e produções que visam, por um lado, valorizar e comemorar o que o campo da Educação Química brasileira vem produzindo ao longo de mais de duas décadas de trabalho e, por outro, problematizar essa produção no sentido de sempre qualificar os debates e investigações, buscamos com este texto colaborar com as discussões a partir de uma análise empreendida durante os estudos de doutorado do primeiro autor. Tomando como foco a Educação Química, foi investigada a produção do discurso dessa área, buscando evidenciar e assinalar a emergência de enunciado(s) que a organizasse(m) (Foucault, 2011). De modo geral e conforme explicitaremos, evidenciamos que, para o campo da Educação Química, sistematicamente se faz presente e ronda as práticas um enunciado que remete à necessária existência de um centramento no sujeito aluno do processo, dando-se destaque a seu nível cognitivo. Esses elementos marcam a ação de algo que, por conta de sua constituição enunciativa, organiza as práticas, regula os ditos e encaminha ações desse campo que constitui e do qual é, imanentemente, constituído.

Neste texto, para dar conta de analisar a produção do discurso e do enunciado que emerge no campo da Educação Química, realizaremos um caminho que passará pela explicitação da escolha de utilização da análise de discurso ao longo da investigação, pela constituição do corpus da pesquisa e os pressupostos teóricos tomados e, efetivamente, pelos elementos analíticos que emergiram. Desse modo, colaboramos, por um lado, com a valorização e comemoração do desenvolvimento dessa área, assim como, por outro, realizamos uma reflexão e análise daquilo que se consubstancia numa comunidade que atua, milita e produz junto e a partir da revista Química Nova na Escola.

\section{A escolha de um modo particular de olhar para o estudo: a análise de discurso}

Não é estranha à comunidade da Educação em Ciências, e da Educação Química em particular, a utilização da análise de discurso como uma ferramenta teórica para o desenvolvimento das pesquisas (Nardi, 2007; Martins, 2007). Em função de ser uma proposta plural e difundida a partir de diferentes vieses teóricos, existem múltiplas linhas de pensamento que tratam sobre ela (Caregnato e Mutti, 2006; Pinhão e Martins, 2009). No campo geral de investigações em Educação e no campo linguístico, a variação entre um grupo e outro se faz, sistematicamente, a partir de como estes compreendem a noção de discurso.

Em relação à Educação Química, seguidamente há apropriação da análise de discurso a partir de linhas teóricas tais como, por exemplo, as defendidas por Orlandi (Ferreira e Queiroz, 2011; Santos e Queiroz, 2007; Nardi e Almeida, 2007) e Bakthin (Cirino; Souza, 2008; Sepulveda; El Hani, 2006). Ainda, tal é a multiplicidade de modos de trabalho com as noções de discurso que, na atualidade da Educação Química, é crescente a utilização da integração de uma vertente da análise do discurso com outra da análise de conteúdo a partir daquilo denominado como Análise Textual Discursiva (Galiazzi e Ramos, 2013; Moraes e Galiazzi, 2007; Galiazzi e Moraes, 2006; Moraes, 2003).

Dada a reconhecida importância da análise de discurso, nossa pesquisa também se localiza nesse campo teórico-analítico. Partindo de questões como: quais seriam e como se construiriam as regras do jogo que é traçado quando nós trabalhamos numa aula de química? O que se entende e como se organizam o que se diz serem conteúdos básicos no trabalho de uma química pensada para a escola? Quais seriam esses? Como cada sujeito é inserido nesse espaço e nele deverá atuar? De que aula de Química efetivamente nós aprendemos a falar, falamos e buscamos que nossos alunos falem ao longo de suas/ nossas aulas? Em suma, podemos coagular essas questões de pesquisa em: como, na atualidade, descrever e explicar um jogo que age em cada cena vivenciada, em cada aula realizada, que (re)atualiza conceitos, propõe novas práticas, explode ou concentra diferentes posicionamentos?

Tendo em vista essas questões, percebemos a potencialidade de utilização da análise de discurso em nossa investigação. Todavia, em face da pluralidade de noções e conceituações a utilizar, vimos como apropriado a essas questões um modo particular de pesquisa, traçada com base nas ideias de Michel Foucault e autores associados. Estes nos possibilitaram compreender nosso objeto de pesquisa, a Educação Química, e os elementos de sua constituição num nível arqueológico e genealógico. Isso porque, diferentemente das análises de discurso usualmente empreendidas, a análise com base no ferramental foucaultiano permite analisar as regras de produção de um discurso, suas relações com outros discursos e sua dispersão, bem como permite enfatizar as lutas de nível microfísico (Foucault, 2013), afastando-se, ao mesmo tempo, de questões semióticas, ideológicas, de mediação ou centradas num imaginário. Esse tipo de investigação propõe não apenas dar destaque a "grandes" pesquisas ou "pesquisadores 
representativos" (Nardi e Almeida, 2007), mas evidenciar uma dispersão das falas, dos ditos, dos tempos nos quais o discurso é produzido. Isso permite considerar diferentes sujeitos, ditos e falas dispersas, que se organizam a partir de um ponto de controle do discurso, que nos possibilita discutir e nos apropriar de um enunciado que ordene esse campo, que trace suas regras e encadeamentos. Se, de uma perspectiva, Nardi e Almeida (2007) investigaram a constituição da área de Ensino de Ciências e Pinhão e Martins (2008) analisaram as propostas de análise de discurso empreendida no Brasil entre 1998 e 2008, as conceituações foucaultianas nos permitiram diferenciar-nos de estudos como estes ao pôr em evidência os elementos a partir dos quais o campo da Educação Química se organiza e, assim, se constitui, dando destaque à produção do(s) seu(s) enunciado(s).

Isso se relaciona com a possibilidade de estranhamento entre aquilo que sistematicamente vem sendo produzindo e o olhar que esse tipo de pesquisa estabelece, pois tal perspectiva exige o rompimento de metanarrativas, ou seja, exige uma explosão das verdades transcendentais assumidas de pronto. Essas verdades podem ser definidas como algo tratado como se já fosse válido mesmo antes de sua proposição; seriam verdades em si. E vimos isso ser recorrente tanto nos trabalhos citados quanto nas análises que efetivamos nas produções da comunidade, que traziam falas a respeito dos conteúdos escolares de Química, das estratégias utilizadas, dos próprios sujeitos dessa área (alunos, professores, pesquisadores, autores, etc.), dentre outros elementos. A cada momento que investigávamos as questões propostas e seus desdobramentos, nos deparávamos com verdades que, ao serem postas de chofre com um aparato histórico (às vezes ainda recente), se viam problematizadas.

Num sentido geral, esse tipo de destaque, afastamento, negação e problematização de metanarrativas não são encontrados na grande maioria das bases conceituais de análise de discurso usualmente empregadas, uma vez que estas, em certo ponto, partem, justamente, de noções empregadas numa coletividade, as quais têm por base uma noção transcendental.

A partir do referencial utilizado (ainda de emprego incipiente no campo da Educação em Ciências), evidenciamos um modo de olhar distinto para os acontecimentos, ações, organizações, verdades e dinâmicas que ocorrem e que são marcados nos trabalhos publicados dessa área, não compreendendo estes apenas como inseridos num campo, mas como acontecimentos que partilham, reforçam e produzem determinadas verdades constituidoras desse campo.

A análise de discurso aqui utilizada permite olharmos de um modo distinto de outros já recorrentes e estabelecidos no campo no qual nos inserimos. Isso implica, em vez de contradições e exclusões, em uma colaboração, por diferentes pontos de ataque e investigação, de nosso estudo com as discussões já presentes e vindouras, mesmo que em outros referenciais analíticos, no campo que analisamos e nos integramos.

\section{Discurso e poder: bases para uma análise}

Uma vez explicitadas as ideias gerais que assumimos para a análise de discurso com base nos estudos foucaultianos, cabe desenvolver, brevemente, alguns elementos conceituais centrais com os quais operamos ao longo da pesquisa - que não são ainda tão usuais no campo da Educação em Ciências - o discurso e o poder.

\section{Discurso}

Nosso trabalho considerou o discurso como prática - e isso é fundamental. A ideia de que não há nada por detrás ou por debaixo dele, mas apenas em seu nível de existência, em seu nível de prática, é a base deste trabalho. Em Foucault, tomamos o discurso como algo complexo, de modo que

(...) gostaria de mostrar que os "discursos", tais como podemos ouvi-los, tais como podemos lê-los sob a forma de texto, não são, como se poderia esperar, um puro e simples entrecruzamento de coisas e palavras: trama obscura das coisas, cadeia manifesta, visível e colorida das palavras; gostaria de mostrar que o discurso não é uma estreita superfície de contato, ou de confronto, entre uma realidade e uma língua, o intrincamento entre um léxico e uma experiência; (...) Certamente os discursos são feitos de signos; mas o que fazem é mais que utilizar esses signos para designar coisas. É esse mais que os torna irredutíveis à língua e ao ato de fala. É esse "mais" que é preciso fazer aparecer e que é preciso descrever (Foucault, 2009, p. 54-55, grifos nossos).

Quando fala do discurso, Foucault pinta um cenário que vai além daquilo que está somente na relação entre as coisas e as palavras; que não se limita numa simplicidade ingênua, mas que se desenvolve sobre um processo complexo.

Assumir isso implicou em esclarecer algumas condições para a constituição dos discursos: primeiramente, o discurso em nível de prática apresenta uma temporalidade, porém sua cronologia não é exatamente cumulativa, isto é, o discurso nesse viés tem uma relação com o tempo que não é de direta acumulação ou sobreposição, mas de ocorrências, retiradas, novas proposições e esquecimentos.

Em segundo lugar, desde a consideração da formação de uma teia discursiva, de uma temporalidade e das questões que mobilizam a pesquisa, é necessário conceber a existência de regras de formação como condição para o discurso. Ele é controlado, selecionado, organizado e redistribuído, pois necessita ser pensado segundo determinados jogos que tornam possível sua constituição (Foucault, 2011). Conforme bem sumariza Fischer (1996, p. 106): 
A formação discursiva deve ser vista, antes de qualquer coisa, como "princípio de dispersão e repartição" dos enunciados (idem, p. 124), segundo o qual se "sabe" o que se pode e o que deve ser dito, dentro de um determinado campo e de acordo com uma certa posição que se ocupa neste campo. Ela funcionaria como uma "matriz de sentido", e os falantes nela se reconheceriam, porque as significações ali parecem óbvias, naturais.

Utilizar essas conceituações de discurso neste estudo marca a necessidade de alguns elementos do discurso da Educação Química estarem presentes para se considerar um dito incluído em suas fronteiras. Ou seja, é necessário que qualquer pronunciação ou ato, para serem incluídos neste campo, sigam determinadas regras de formação. Assumir isso para o discurso é colocar, nesta pesquisa, suas questões iniciais e referencial teórico lado a lado; é espreitar os jogos que desejamos estudar na constituição da Educação Química.

Terceira condição: em nosso trabalho, o discurso será compreendido e definido a partir de um de seus elementos centrais, o enunciado. Isso implica em dizer que, para demarcar o discurso acerca da Química trabalhada na escola, cuja centralidade de investigação está na atual Educação Química, investigada por meio da revista Química Nova na Escola, esquadrinhá-lo será um estudo sobre o enunciado que o sustenta.

A partir dessa ideia, nosso estudo colocou em evidência a produção de um enunciado que reiteradamente vimos se dispersar e aparecer nas falas e propostas da Educação Química analisada. Isso implicará na constituição de relações possíveis de se estabelecer nesse conjunto discursivo, uma vez que, segundo Foucault (2009), nos referiremos à raridade dos enunciados e sua dinâmica.

Essas apropriações realizadas sobre a conceituação de discurso fizeram nossa discussão e estratégia de trabalho se dirigirem à investigação desse enunciado a partir de algumas perguntas: como ele se materializa no campo da Educação Química? Quais seriam sua forma e efeitos em outros elementos do discurso da Educação Química? Quais cruzamentos ele perpassa e sustenta nesse campo? A partir de Foucault (2009) sondamos a constituição desse enunciado, compreendendo que ele exigia quatro elementos: i) apresentar um espaço de diferenciação de outros enunciados, ii) ter uma materialidade, iii) abrir um espaço a ser ocupado por posições subjetivas e iv) possuir um campo no qual ele se associe a outros enunciados. Essas exigências se relacionam diretamente com os domínios que investigamos nos materiais analisados: i) o domínio das posições subjetivas, ii) das escolhas estratégicas, iii) da formação dos conceitos e iv) da formação dos objetos (Foucault, 2009).

\section{Poder}

Enquanto, de um lado, o discurso será prática, de outro, as relações que essa prática exige correspondem, também, à ideia de poder. Para compreender isso, cabe dizer que tomaremos o poder a partir de uma série de negações gerais. São elas: $O$ poder não será i) um conjunto de instituições que garantem a sujeição de uns e outros; ii) algo que possui um ponto central, origem ou elemento principal; iii) algo que se possua ou possa ser trocado; iv) algo global ou unitário, que dê conta de tudo do mesmo modo; v) algo que se desdobra sobre uma idealidade totalmente abstrata ou imaterial.

Essas cinco ideias se relacionam profundamente com a questão do discurso, uma vez que em todas as relações que estabelecemos neste estudo, há uma ação de poder. Assim, ao negar a localização ou emanação de instituições, colocamos o pressuposto de que, ao falar da Educação Química, não analisaremos uma relação e o discurso produzido na escola ou na universidade. Pela perspectiva discursiva adotada, não estudamos a prática dada em um local. Ao contrário, o que há é um processo analítico que apreende relações que constituirão essa escola, esse lugar. Assim, nossos estudos tomam a existência de poderes que percorrem, atravessam e constituem essa escola, os sujeitos, a Educação Química etc., e isso marca mais uma diferença de nossa pesquisa e referencial em comparação àquelas já usuais nesse campo.

Com isso, nossa pesquisa teve por base um poder que se espalha e atravessa vários níveis, ou seja, ele não possui um ponto central, origem ou elemento principal, mas circula. Isso implica em assumir um aspecto relacional a respeito dele. "Rigorosamente falando, o poder não existe; existem práticas ou relações de poder" (Machado, 2013, p. 17) e, se assim for entendido, não é mais viável levá-lo estaticamente para fora dessas práticas e localizá-lo num ponto original, seja este um indivíduo, uma instituição, um acontecimento, uma ideologia, uma situação econômica etc.

Onipresença do poder: não porque tenha o privilégio de agrupar tudo sob sua invencível unidade, mas porque se produz a cada instante, em todos os pontos, ou melhor, em toda a relação entre um ponto e outro. O poder está em toda parte; não porque englobe tudo e sim porque provém de todos os lugares (Foucault, 1988, p. 103).

O poder é ato; somente existe em ação. Com isso, percebe-se que o poder não é único, não se desenvolve ou se aplica de modo igual a diferentes espaços ou sujeitos. Isso significa que ele possui diferentes nuances. De modo resumido: o poder é heterogêneo. Se ele é relação, se ele se vincula ao discurso como prática, as diferentes práticas e relações requerem formas diferentes de poder.

A última negativa que marca a localização teórica deste estudo se refere à necessária materialidade do poder. Embora os discursos, poderes, conhecimentos, saberes, etc. não sejam materiais, não sejam possíveis de serem comprimidos, 
repartidos ou mensurados, só é possível analisá-los nos processos, e, aí sim, esses processos produzem materialidades, efetivamente físicas, como, por exemplo, uma pesquisa materializada nas páginas de uma revista. Segundo Foucault (2011, p. 57-58),

Certamente o acontecimento não é nem substância nem acidente, nem qualidade, nem processo; o acontecimento não é da ordem dos corpos. Entretanto, ele não é imaterial; é sempre no âmbito da materialidade que ele se efetiva, que é efeito; ele possui seu lugar e consiste na relação, coexistência, dispersão, recorte, acumulação, seleção de elementos materiais; não é ato nem a propriedade de um corpo; produz-se como efeito de e em uma dispersão material. Digamos que a filosofia do acontecimento deveria avançar na direção paradoxal, à primeira vista, de um materialismo do incorporal.

Trazer em voga tais elementos significa olhar para as questões iniciais da pesquisa, readequá-las ao desenvolvimento do trabalho e compreender como elas são mobilizadas e envolvem as discussões referentes ao discurso e sua integração necessária ao poder.

\section{Metodologia da pesquisa}

O modo como este estudo compreendeu a análise de discurso, associada às propostas de Michel Foucault e autores próximos a ele, evidencia uma forma particular de constituir a pesquisa como um todo. É nesse sentido que, consoante com os pressupostos gerais apresentados acima e buscando em outras investigações de mesma linha teórica possibilidades de constituição da pesquisa, encontramos na Análise Temática uma potente estratégia analítico-metodológica (ÁlvarezGallego, 2014; 2013; Marín-Díaz, 2012; 2009). Ela evidencia um modo de organizar e fazer emergir, num procedimento só, elementos próprios ao problema de pesquisa, os quais vimos como estando relacionados tanto a questões arqueológicas (Foucault, 2011; 2009; 1987) quanto genealógicas (Foucault, 2013; 2011), sendo a primeira responsável por evidenciar principalmente o discurso e seu elemento fulcral, o enunciado (Foucault, 2008), enquanto a segunda permitiu estabelecer distintas relações no campo estudado e, principalmente, evidenciar relações de poder.

De acordo com Marín-Díaz (2012), a Análise Temática possibilita quebrar com a suposta unidade de cada material, desarticulando-o nas ideias principais que o constituem. Esse processo permite, num momento posterior, identificar recorrências, dispersões, inaugurações e continuidades, fazendo emergir daí possíveis enunciados. Estes permitem rearticular interna e externamente os diferentes materiais analisados, organizando os modos e as forças que agem na elaboração dos ditos, das falas, das práticas do discurso que se analisa.

Uma organização possível do trabalho com a Análise Temática pode ser dada em três grandes movimentos de pesquisa: a) seleção, ordenação e pré-leitura dos materiais; b) tematização dos documentos e; c) leitura crítica e cruzamentos (Álvarez-Gallego, 2014; 2013; Marín-Díaz, 2012; 2009).

Na primeira etapa há o processo de seleção dos materiais que busquem dar conta da própria problematização que se impõe à pesquisa. Em nosso caso, a problematização inicial buscava compreender e evidenciar o modo de produção de um educar em Química. Desejávamos esquadrinhar o enunciado que animava esse campo e os modos como ele era (re)produzido e posto em prática. Ao realizar a primeira etapa de seleção a partir do problema de pesquisa, muitos materiais surgiram, mas, conforme se destacou acima e as primeiras leituras indicaram, a abrangência, a importância e a constante ação da QNEsc no cenário da Educação Química possibilitaram que ela fosse eleita como material de análise.

Após selecionado o primeiro recorte do corpus, pela Análise Temática há a proposta de realização de uma nova leitura ampla daqueles materiais selecionados a fim de criar uma visão da dimensão na qual se projeta a pesquisa. Dessa ampla leitura, do volume de materiais publicados na QNEsc e das etapas de análise, evidenciamos uma quantidade de documentos a analisar para além do necessário a esse tipo de estratégia. Dessa forma, esse processo exigiu a realização de novos recortes, de modo que, neste estudo, foram consideradas para o corpus duas seções da revista: Conceitos Científicos em Destaque e Relatos de Sala de Aula. Embora, em um primeiro momento, pareça haver uma redução da pluralidade de textos apresentados pela revista, salientamos que ambas as seções compreenderam a maior parte de textos publicados no período analisado. Ainda, é mister reforçar que nossa investigação buscou elementos que se organizam no nível da prática discursiva, ou seja, assumiu-se a ideia de dispersão do discurso e, portanto, que as seções incluídas na análise, por estarem num conjunto de uma revista, têm elementos que se cruzam, articulam e colaboram com as seções excluídas do processo analítico. Nesse recorte há, assim, elementos mais basais e construtores do próprio discurso no qual esses textos foram produzidos, que evidenciamos da leitura ampla dos textos da revista. Isso mostra porque nos preocupamos menos com quais conceitos eram problematizados, do que, por exemplo, com o destaque à recorrência, seja numa ou noutra seção, sempre dos mesmos conceitos e, junto a eles, elementos discursivos comuns que os sustentavam. Aliada a essa definição teórica do recorte, a escolha da primeira seção também se pauta em valorizar os modos como a comunidade da Educação Química fala e recebe o próprio campo conceitual da Química e sua existência como disciplina, enquanto a da outra refere-se à Química que se produz na escola, seus temas, conceitos e pressupostos que se relatam. Complementarmente, os editoriais 
também foram analisados em função de sua característica de marcar o contexto de cada número da revista.

Constituído o grande corpus, o segundo processo, de tematização dos documentos, permitiu trabalhar com a dispersão do discurso e com a extensão das relações das forças. Para isso, operamos o fichamento dos textos selecionados para compor o corpus analítico. A proposta de sua organização em fichas busca permitir ao analista a realização de sua explosão em unidades, as quais, ao serem produzidas, não correspondem mais ao texto (embora haja sua referência), mas constituem unidades anônimas, que não pertencem mais a determinado autor e que se inserem num espaço puramente da prática discursiva (Álvarez-Gallego, 2014)ํ.

Uma vez desconstruído o texto, ou seja, postas como dispersão discursiva as unidades criadas, cabe ao analista organizá-las e tematizá-las. Nesse processo, recorrências, repetições e sentidos compartilhados vão compondo um grupo de discursividades. Não apenas estas, as inovações ou, ainda, as exclusões ou rupturas também são importantes à análise, de modo que a articulação de todos esses elementos permite criar uma cartografia do espaço em análise. De modo geral, um exemplo da tematização realizada às unidades fichadas pode ser observado na tabela 1 .
Após as etapas de organização, seleção, pré-leitura e tematização, a última fase do processo metodológico corresponde à leitura crítica das tematizações realizadas e ao cruzamento dos diversos elementos discursivos e das relações de poder constituídas. É nesse ponto que surge a construção do próprio texto-analítico e dos confrontos que nele se apresentam para mostrar o que emerge como resultados da pesquisa.

Embora esse processo seja, à primeira vista, similar a outros já empregados no campo da Educação em Ciências, destacamos que sua diferenciação se dá muito mais no sentido teórico-analítico do que no sentido metodológico-operacional. De modo geral, a ênfase que a Análise Temática traz está sempre voltada ao estabelecimento de relações, à evidenciação da dispersão de um discurso, da regularidade ou modificação repentina de ideias. Esses elementos são fulcrais para o mapeamento das relações discursivas e se diferenciam dos processos de análise de discurso usualmente empregado no campo da Educação Química, como em Ferreira e Queiroz (2011), Sepulveda e El Hani (2006), dentre outros - principalmente por não requerer e nem ser necessário uma discussão quantitativa das frequências ou recorrências, mas sim uma explicitação de suas relações e ação no campo discursivo, a exemplo de Marín-Díaz (2012). Essa análise, ao produzir

Tabela 1: Exemplo de uma unidade de análise para o tema Estratégias e Metodologias. São apresentados o código do tema, o tema ao qual a unidade faz parte, os elementos do tema e dois excertos comentados que deram origem ao tema.

\begin{tabular}{|c|c|c|c|}
\hline \multicolumn{4}{|c|}{ Fichamento do Espaço Dizível - Conceitos e Objetos Discursivos } \\
\hline EDCO10 & $\begin{array}{l}\text { Estratégias e } \\
\text { metodologias }\end{array}$ & $\begin{array}{l}\text {-Centralidade das estratégias de ensino; } \\
\text {-Estratégias e metodologias são as } \\
\text { "responsáveis" pela aprendizagem dos } \\
\text { conceitos e conteúdos químicos; } \\
\text { - Sucesso do trabalho com os conceitos } \\
\text { químicos buscado por meio da estratégia } \\
\text { empregada; } \\
\text {-Pensar nas estratégias é fazer um } \\
\text { esforço para se distanciar do ensino } \\
\text { tradicional; } \\
\text {-Estratégias e metodologias como } \\
\text { elementos que reforçam os conteúdos } \\
\text { (ao não problematizá-los); }\end{array}$ & $\begin{array}{l}72 \\
\text { Reflete-se sobre as metodologias e estratégias, } \\
\text { não sobre os possíveis conhecimentos que } \\
\text { seriam mais produtivos: "Além de refletir sobre as } \\
\text { metodologias e estratégias utilizadas para efetivar } \\
\text { a inclusão, eles também romperam preconceitos } \\
\text { e expandiram horizontes e possibilidades". (p. 32) } \\
165 \\
\text { A estratégia é complexa e aberta, mas tem-se de } \\
\text { voltar aos conteúdos tradicionais de ensino: "O } \\
\text { conhecimento proporcionado pelo enfrentamento } \\
\text { de problemas autênticos demanda uma construção } \\
\text { coletiva paulatinamente pensada, por meio do } \\
\text { ativo envolvimento do aprendiz e da mediação } \\
\text { do professor, além de estratégias particulares } \\
\text { de ensino. A própria definição de temas deve ser } \\
\text { pensada no âmbito de cada contexto em que a } \\
\text { escola está inserida, segundo o interesse dos } \\
\text { alunos e de forma que permita uma convergência } \\
\text { para os tópicos do conteúdo tradicionalmente } \\
\text { planejados". (p. } 7 \text { ) }\end{array}$ \\
\hline
\end{tabular}


os cruzamentos, explicita uma ordem discursiva do próprio conjunto que se investiga.

Em termos de estabelecimento do corpus, de acordo com as conceituações trazidas na pesquisa, os editoriais e as duas seções escolhidas foram analisados desde o primeiro volume da revista (1995), até o momento de composição do corpus (agosto de 2014), compreendendo um período de 19 anos e resultando em 198 documentos (equivalentes a mais de um terço dos artigos publicados). A cada um deles foi atribuído um número entre 2 e 199, de modo que as análises que aparecerão no texto farão referência a esse número de identificação.

Por fim, cabe destacar que, no processo de construção da pesquisa, em função das conceituações mobilizadas, também foi preciso buscar um espaço de diferenciação do discurso analisado. Um campo discursivo, ao ser pesquisado, pode ser evidenciado em sua diferenciação a outro campo discursivo. Dessa forma, é essa a função que outro dos materiais utilizados em nosso estudo tem: o de marcar a diferenciação de um espaço de discursividade para outro, salientando suas distâncias, regras e, em certa medida, recorrência. Embora não seja o foco deste texto assinalar com tamanha intensidade essas diferenciações, é preciso reiterar a importância ao processo analítico que esse espaço de diferenciação tem. Assim, buscamos no livro de Arnaldo Carneiro Leão, de 1936, intitulado Química: iniciação ao estudo dos fenômenos químicos - de acôrdo com o programa oficial para a terceira série a constituição desse espaço. A escolha desse livro se justifica por sua presença (historicamente localizada) fora do eixo demarcado pela Educação Química. Em termos dos critérios utilizados para elegê-lo como espaço de diferenciação, destacaram-se: 1) a acessibilidade do tipo de material escolhido (livro didático); 2) a autoria, disponibilidade e distribuição nacional; 3) a apresentação de uma relação com as questões oficiais de sua época, como o programa oficial apresentado, a política nacional, etc.; 4) a presença, em algum momento, de uma preocupação em ensinar química e discuti-la no espaço da escola. Assim, embora outros materiais apresentassem esses elementos, apenas o livro selecionado expôs todos eles de modo integrado. Ainda, uma análise global nos demais materiais encontrados evidenciou que eles apresentavam os mesmos conteúdos, no sentido de que continham tanto conceitos, quanto modos de falar, de propor ideias, muito semelhantes.

As estratégias utilizadas de leitura geral, pré-análise, desconstrução, tematização e diferenciação possibilitaram evidenciar a emergência de cinco grandes temas que vimos recorrentes e constituintes de um discurso da Educação Química. Ao estudar esses temas gerados na Análise Temática, pudemos identificar uma ideia geral que os reunia sob um mesmo aspecto e, de certo modo, os regulava, sendo esta compreendida como o próprio enunciado. Sobre os temas, eles podem ser caracterizados como: a recorrência de uma formação para cidadania, o centramento em estratégias didáticas, a necessidade da presença de uma interdisciplinaridade, a profunda relação entre a disciplina de química e a cognição e, por fim, a emergência de um determinado tipo de aluno que se forma ou se deseja formar nesse espaço. Todos esses temas, ao serem analisados, encaminharam a um núcleo comum que os organizava, o qual compreendemos ser a função enunciativa desse discurso. Tal função pode ser expressa a partir de um tipo muito especificado de sujeito aluno, o qual apresentará uma estrutura cognitiva determinada, sendo tomado como ponto segundo o qual os demais sujeitos e as próprias práticas desse processo deverão se organizar.

\section{O discurso da Educação Química: a emergência de um enunciado}

Todo o caminho analítico buscou, na pesquisa realizada, esquadrinhar o discurso produzido e efeito de um fazer Educação Química (sua prática) a partir de um espaço reconhecido de investigações e publicização de ações, a revista Química Nova na Escola. Nesse processo, os temas constituídos puseram em evidência determinado enunciado organizador do discurso desse campo. Para melhor compreendê-lo, faz-se necessário apresentar cada tema que emergiu na análise e como estes contribuíram para a marcação do enunciado e, assim, do próprio discurso.

\section{A cidadania}

De que modo podemos afirmar que a cidadania é um tema que se faz presente no discurso da Educação Química e é um dos elementos que o organiza? Percebemos que o chamamento à formação cidadã, à produção de um sujeito cidadão, à preocupação com a vida, com a tomada de decisão e o posicionamento de sujeitos atuantes é recorrente em grande parte dos textos. Obviamente, isso não ocorre somente na Educação Química analisada, mas a perpassa e se coloca como tema de seu discurso.

De modo geral, identificamos que a noção da cidadania passa a ser objeto de problematização a partir de meados do século XX. Em termos de episódios globais, há o fim da Segunda Guerra Mundial; surge um grande número de novas proposições científicas que invertem uma série de crenças particularmente aquelas referentes às noções relativísticas e quânticas -, bem como o encaminhamento à cientifização alavancado pela Guerra Fria; novos modelos estéticos passam a vigorar, os desdobramentos do que posteriormente se chamará globalização passam a ter efeitos mais intensos; a informatização dá novas dinâmicas às relações das pessoas com as coisas e com os acontecimentos, etc. No contexto brasileiro, o final do período de ditadura, a valorização dos princípios democráticos, a conclamação da população a ser ativa nos processos decisórios da administração do Estado, a expansão dos modos de comunicação no território, a modificação das relações e modelos econômicos adotados, dentre 
muitos outros elementos, contribuem para a produção de determinado modo de sujeito e de formas como esse sujeito lida com os saberes e conhecimentos produzidos.

Nas diversas modificações que ocorrem no mundo nessa segunda metade do século XX, uma delas é fundamental para o campo das Ciências - embora nunca isolada - para a intensificação do destaque e chamamento dessa cidadania. Conforme Lopes (1998, p. 128), "situa-se, então, no período pós-guerra, o início de uma fase de valorização do ensino de Ciências, especialmente associado à possibilidade de desenvolvimento científico e tecnológico". As guerras auxiliaram nesse destaque a partir do ponto em que os próprios sujeitos ocupantes do lugar de mais iluminados, os cientistas, viabilizaram uma preocupação com a manutenção da vida na face da Terra a partir dos desenvolvimentos científicos (nomeadamente, as armas de destruição em massa, os novos métodos produtivos, o consumo exacerbado, o gasto energético e não renovável, dentre outros). Não apenas aí, a própria conquista de outros lugares pelo ser humano (como as profundezas do oceano, ou a lua e outros planetas do sistema solar), muito incentivada pelas preocupações bélicas, promoveu a emergência de discussões acerca dos limites éticos, dos direitos humanos, do alcance aceitável para tais desenvolvimentos ${ }^{2}$. Segundo nossa investigação pôde constatar, esse processo de deslocamento de uma visão centrada no conhecimento iluminado para um conhecimento mais atuante e implicado vai marcando a emergência do discurso da Educação Química.

Esse conglomerado de acontecimentos possibilitou um movimento de valorização da vida, cujo principal argumento estava na existência de determinados direitos (não só humanos) que deveriam ser introjetados nos indivíduos. Não bastam somente cultura, polidez, cortesia ou urbanidade - elementos básicos à vida civilizada -, mas faz-se necessário, nessa temporalidade ainda recente de pensamento, o foco na própria objetivação de direitos e deveres - que balizam a noção de cidadania (Santos e Schnetzler, 2014).

Sendo assim, se uma parcela significativa desse deslocamento estava relacionada aos avanços científicos, nada mais natural (na concepção que vai emergindo nesse momento histórico) do que buscar nas próprias ciências um modo de responsabilização pelos desdobramentos daquilo que produziriam, e nada mais intenso e menos custoso do que operar por meio da instituição escolar essa formação cidadã. É justamente aqui que a Química ganha seu destaque; é nesse bojo que há uma proveniência (Foucault, 2013) daquilo que emergirá enquanto discurso de uma Educação Química.

É nesse sentido que a prática discursiva dessa área irá se repartir nos vários documentos analisados e reatualizar, seguidamente, a questão cidadã. Neles ela aparecerá ora como um movimento indivíduo-coletividade, ora como compromisso (social, ambiental, ético, etc.), ora como direito (implicado com deveres) dos sujeitos que estão no mundo, ora como a necessária tomada de decisão e posicionamento desses sujeitos.
Trechos como os citados abaixo, aliados aos demais analisados, permitem identificar tais elementos:

A partir da compreensão de conceitos científicos relacionados à temática proposta, tem-se o desenvolvimento das habilidades básicas relativas à formação da cidadania, como a participação e a capacidade de tomada de decisão, pois trazem para a sala de aula discussões de aspectos sociais relevantes, que exigem dos alunos posicionamento crítico quanto a sua solução (Documento 69, p. 34).

Trata-se de formar o cidadão-aluno para sobreviver e atuar de forma responsável e comprometida nesta sociedade científico-tecnológica, na qual a Química aparece como relevante instrumento para investigação, produção de bens e desenvolvimento sócio-econômico e interfere diretamente no cotidiano das pessoas (Documento 123, p. 18).

$\mathrm{Se}$, ao esboçar a questão do discurso, trouxemos a ideia de que sua análise busca evidenciar algo a mais, note-se que a questão que se coloca aqui não é a definição ou o detalhamento que qualquer um dos trechos acima opera sobre o conceito de cidadania, ou mesmo se o termo aparece ou não. O que se coloca em pauta é mais do que isso. Do ponto de vista trazido em nossa pesquisa, ressalta-se que a noção geral de cidadania se constitui como um dos elementos para se produzir a Educação Química. Ensinar Química estará reiteradamente posto como uma ação "que contribua para a formação de cidadãos cada vez mais críticos e bem informados" (Documento 3, p.88). Nesse sentido, a cidadania opera quase como um objetivo desse campo, tal é a sua constância nas falas, de modo que não causam estranhamento trechos que afirmam que "o ensino de Química no Ensino Médio deveria ter como foco as 'explicações químicas' necessárias à vida do aluno/cidadão" (Documento 105, p. 19).

Mas a cidadania não é o único tema que é possível constituir ao longo da análise do discurso da Educação Química e na sondagem de seus enunciados. No movimento complexo que há na produção de uma cidadania nesse campo, cada vez mais há a incidência de outros elementos que atuam no nível da proveniência a esse discurso. Tal será também o caso da (re) afirmação da centralidade de se pensarem estratégias didáticas na Educação Química.

\section{As estratégias didáticas como objetos do discurso da Educação Química}

Inicialmente, é preciso que explicitemos dois elementos fundamentais do discurso: seus objetos e seus conceitos. Em termos gerais, o primeiro seria definido como um elemento discursivo que não necessitará de qualquer explicação; será, 
em certa medida, naturalizado em dado discurso e aparecerá nele como algo inerente a ele. O segundo, por sua vez, seria organizado a partir da ideia de ser um componente do discurso que abarca ou conglomera outros elementos (Álvarez-Gallego, 2014; Foucault, 2009). É desse modo que os conceitos usualmente virão acompanhados de outras noções que os expliquem - e talvez esta seja a maior oposição de diferenciação entre objeto e conceito: este deve ser explicado, tem de contemplar em sua existência outros elementos mais, enquanto aquele, quanto mais incólume passar, mais solidificado estiver, mais intensamente será um objeto do discurso.

É a partir dessa assunção que poderemos discutir como as estratégias didáticas (também entendidas como metodologias) cada vez mais formam um tema nesse discurso, pois evidenciamos um sistemático recurso a elas enquanto algo não questionado, não problematizado, ou seja, as estratégias operando como um objeto discursivo.

Embora tenhamos percebido que se problematizem as estratégias em si (por exemplo, se proponha ora uma atividade laboratorial, ora uma dinâmica de grupo, ora uma atividade de visitação), a centralidade de sempre recorrer a algum tipo de estratégia didática para aprimorar as aprendizagens não perfez qualquer problema para a Educação Química. Basta ver, em várias pesquisas, que,

(...) ao organizar as atividades a serem desenvolvidas, utilizei estratégias de ensino que favorecessem a participação ativa dos estudantes no processo de construção de conceitos e de (re)significação dos temas trabalhados. Com base nesse pressuposto, no ano letivo de 1996 procurei estruturar atividades a serem desenvolvidas em torno de dois temas centrais: "Propriedades específicas dos materiais" e "Transformações Químicas". Para os dois temas, priorizei abordagens que privilegiassem o nível macroscópico do conteúdo (...) (Documento 156, p. 16).

Cruzando esse trecho com muitos mais construídos por meio da Análise Temática, as estratégias cada vez mais se ratificaram como uma forma natural e mais potente de trabalhar e organizar a química escolar. Ainda, e por implicação quase direta, recebem boa parte da fatia de responsabilidade pela aprendizagem de seus alunos:

(...) sabemos que a escola deve trabalhar a realidade dos alunos e transformá-los em cidadãos conscientes e que o processo de aprendizagem pode ser mediado pela ação do professor com o uso de novas metodologias, que podem despertar o interesse em aprender a cada dia (Documento 19, p. 189).

Com isso, o sucesso do trabalho com os conceitos químicos será buscado por meio da estratégia empregada - a qual deverá ser, por questão de ordem discursiva, diferente daquela entendida como tradicional (memorística, não dialógica, bancária, uniplataforma, etc., que estaria inserida numa racionalidade já superada - tal como a do livro de Arnaldo Carneiro Leão tomado como espaço de diferenciação). Outros trechos reiteram:

Experiências envolvendo a utilização de computador, internet, sistemas multimídia, televisão e cinema na educação em química também são escassas e não devido à falta de equipamentos e recursos nas escolas, mas devido à falta de uma formação didática e tecnológica que permita aos professores conhecer, dominar e integrar essas ferramentas e elementos culturais em suas aulas. É preciso, portanto, formar professores que saibam lidar com essas ferramentas em sala de aula (Documento 21, p. 175).

No movimento de análise, evidenciamos que o centramento recorrente das ações de sala de aula nas estratégias tem por efeito algo muito interessante: a quase inexistência de trabalhos que, por um lado, questionem qualquer conceito químico ${ }^{3}$ ou, por outro, que não apresentem alguma proposição de aprimoramento do ensino ou aprendizagem passando por meio de estratégias didáticas ${ }^{4}$. E aqui nos limitaremos apenas a comentar (por conta do espaço deste texto) que, a todo o momento, os conceitos químicos também não são questionados, ou seja, também são tomados como objetos discursivos. Sistematicamente, se há algum questionamento de que determinado grupo de sujeitos-alunos não compreenderam algo da Química, usualmente opta-se, nesse campo de discursividade, por alterar a estratégia didática utilizada para que tal conceito seja aprendido. Em nenhum momento opta-se por questionar a validade ou a importância desse conceito químico. Isso não tem relação com as seções da revista incluídas ou excluídas da análise, pois, nas primeiras leituras do conjunto geral de textos publicados na QNEsc, também identificamos tais elementos. Dessa questão, um pensamento que construímos ao final da análise - reforçado por discussões como as de Lopes (2013; 2004), que tratam de elementos curriculares nas políticas públicas e sua relação com os processos complexos de seleção e exclusão de saberes válidos - remete a uma conjectura de que, talvez, na ordem discursiva que se apresente, não caiba à escola ou às práticas que nela se constituem discutir os conceitos químicos; a escola não seria autorizada a isso.

Se, conforme já apontou Díaz (2012), a visibilidade total é um sonho, havendo sempre o visibilizável e, portanto, parte sombreada, quando falamos das estratégias enquanto objeto do discurso as colocamos no nível do visível (ainda que nunca totalmente) no discurso da Educação Química. É desse modo que, operando como objeto discursivo, as estratégias colocam sempre uma questão de não evidenciação de outros problemas 
que não sejam de método. No Documento 26, por exemplo, depois de se referir a uma série de pesquisas que apontam problemas de compreensão dos conceitos de elemento, substância e mistura, finaliza-se com a solução: há que se "introduzir em sala de aula abordagens diferenciadas que tratem o conhecimento de forma contextualizada e que provoque mobilização, motivação e aprendizagem nos alunos" (p. 76).

Há outros objetos discursivos na Educação Química, isso é certo. Evidenciamos outras nuances, ocorrências e aparições. Todavia, no tênue limite entre cegueira e não-visibilidade discursiva, as estratégias desempenham sua função de objetos discursivos de modo intenso: elas não são objeto de problematização. Embora se repitam e se reatualizem, elas não são problematizadas a partir do ponto em que não se considera possível outra solução à não-aprendizagem ou ao insucesso e à desmotivação do que a produção de mais e mais estratégias. Mesmo que os conceitos químicos possam ser problemáticos, estes também não se questionam, mas acreditamos que isso somente funcione por que há sempre a recorrência inquestionada à alteração, adaptação ou proposição de novas estratégias. Embora se criem múltiplos modos de operar em sala de aula, é sempre à noção geral de estratégia que se recorre; é sempre pelas estratégias que passam as preocupações com a formação dos alunos e com sua (não-)aprendizagem; é, portanto, nelas que evidenciamos mais um tema que percorre o discurso da Educação Química, forma-o e dele é efeito. Mas ainda nem estratégias, nem cidadania se bastam na produção desse discurso. Sigamos com mais temas evidenciados.

\section{A necessária interdisciplinaridade}

O outro tema que percorre e constitui o discurso da Educação Química pode ser determinado como uma necessária interdisciplinaridade. Em sua ação, evidenciamos que a interdisciplinaridade é posta em prática tanto como um tipo especial de estratégia (ao lado de outras que evidenciamos) quanto uma lógica que se organiza e é legitimada a partir de determinada leitura possível do mundo. Se a organização disciplinar das coisas, sua integração, expansão e distribuição constituem a lógica que, na atualidade da escola, ainda se opera (Gallo, 1997; Veiga-Neto, 1996), não menos se espera que a interdisciplinaridade seja colocada como necessidade de compreensão e articulação desse mundo fragmentário.

O principal objetivo é construir o conceito de interdisciplinaridade, e de que fatos, acontecimentos históricos e desenvolvimento tecnológico, assim como qualquer atividade humana, não podem ser analisados sob um único ponto de vista, mas relacionando todas as áreas do conhecimento (Documento 52, p. 90).

É, então, agindo pelo modo de ver o mundo e pela potência de organizar uma série de conteúdos que circulam nessa Educação Química, que a interdisciplinaridade urge nas falas desse campo.

(...) a prática docente está comprometida com um currículo rígido, que prestigia conteúdos desconectados entre si, numa ausência de interdisciplinaridade e, sobretudo, da realidade dos alunos, situação que cria a desvalorização da aula como um local de construção e mudança, tanto dos alunos como dos professores (Documento 16, p. 220).

A apresentação dos conteúdos relacionados às Ciências Naturais durante o Ensino Médio ocorre de maneira fragmentada, provocando o fracionamento do conhecimento em disciplinas isoladas. A configuração e o âmbito dessas disciplinas são freqüentemente estabelecidos pelos livros didáticos, que delimitam os conteúdos e a seqüência dos tópicos (Krasilchik, 1998). Nesse contexto, a discussão de temas complexos, como as questões ambientais e os problemas de saúde, fica prejudicada devido à necessidade de combinar conhecimentos de diferentes disciplinas (Morin, 2002) (Documento 121, p. 19).

Dos trechos acima, vê-se que as falas requerem o fazer interdisciplinar (mesmo sem explicitar o termo). Ainda assim, mais do que requerer e indicar a interdisciplinaridade como desejável, essas falas marcam sua prevalência principalmente a partir do contraponto com determinadas formas e práticas diferentes dela (como a disciplinaridade) e, sob o jogo de verdade que se estabelece nesse discurso, estas seriam menos produtivas do que uma proposta interdisciplinar (mais abrangente). Esses elementos constituem, então, um posicionamento disperso e difundido nos trabalhos que assumem a interdisciplinaridade como necessária à Educação Química. Caso essa lógica não seja empregada, não apareça ou se o que se desenvolve não tem abertura a ela, tal prática será criticada ou, num extremo, não estará incluída nesse campo.

Quando esses elementos são tornados visíveis, põe-se a questão de que, se algo é tido como melhor e mais abrangente, então deverá ser buscado com todas as forças. Considerar isso é se colocar no jogo estabelecido; é perceber os poderes em circulação e sua potencialidade produtora nesse e desse discurso; é compreender que uma fala como "o mundo do vivido, do analógico, do imediato, são contextos que a atividade interdisciplinar precisa atingir, para dissolvê-los e transformá-los em estruturas de pensamento, de ciência, de conhecimento" (Documento 131, p. 30) torna visibilizável, por meio de uma força, o poder que age e se coloca na imanência da Educação Química, integrando no feixe de seu discurso a necessidade dessa interdisciplinaridade. $\mathrm{O}$ conjunto dessas ideias indica a proeminência que há do movimento que vê a necessidade de realizar a ampliação da disciplina. 
A partir do ponto em que a questão da cidadania aparece no campo da Educação em Ciências e a ela se coaduna um centramento nas estratégias, surgindo modos considerados mais potentes de ler e integrar o mundo, aos poucos a análise encaminha elementos que serão recorrentes e que determinarão um perfil de ação do discurso de uma Educação Química.

\section{Disciplina e Cognição}

Outro tema que emerge articulado aos demais já assinalados é a relação entre a aprendizagem da disciplina Química (no contexto da Educação Química) e sua relação com a noção de cognição. Este tema pode ser evidenciado a partir da emergência, conjunta, de um sujeito do processo de produção de saberes e conhecimentos.

Tal problematização pode ser compreendida quando, a partir da segunda metade do século XX, destaca-se uma preocupação com a forma como os sujeitos organizam seu pensamento para pensar. Nesse sentido, se, anteriormente, as proposições de Descartes já apontavam um humano que pensa e existe, os desdobramentos que ocorreram na episteme moderna trazem o próprio pensamento como objeto de saber. Emergem questões que a resposta cartesiana já não dava conta: como o pensamento se organiza? Como ele se estrutura ou poderia se estruturar? Como poder trabalhar de modo a potencializar a ação desse pensamento? No caso de pensarmos a Química e seus processos educativos, entender o pensamento é um recurso plausível? Em resumo, e jogando com a proposição de Descartes, as perguntas que surgem em dado momento e que terão efeitos no campo da Educação Química podem ser assumidas como: posto que eu penso, como eu penso e organizo meu pensamento?

É importante marcar que tais questionamentos emergem de modo interessado a partir de vários campos do conhecimento, o que resulta, em dado momento, em uma busca por destrinchar esse pensamento para sobre ele operar. Os efeitos disso são extremamente potentes e produtivos, pois conhecer esse pensamento pode ser útil para várias finalidades, tais como a de buscar as formas de determinado sujeito expandir melhor seus modos de pensar, de qualificar esse pensamento e de melhor confrontá-lo.

Essas ideias são caras ao campo da Educação porque, a partir da segunda metade do século XX, um de seus intuitos passou a ser buscar modos de possibilitar mais e mais a qualificação do pensamento. Isso implica na própria constituição da aula de química, que tenderá a organizar-se "para ensinar conceitos químicos de forma integrada à estrutura cognitiva dos alunos e à sua realidade" (Documento 76, p. 15) ou que buscarão distanciar, por exemplo, o estudo da química de "um simples processo mecânico de reorganização de fórmulas, que em nada contribuem para o desenvolvimento cognitivo do aluno" (Documento 104, p. 15).

É assim que, centrando o foco neste campo, produz-se uma vontade de saber sobre essa mente e seu pensamento, que implica, claro, em uma questão de poder, pois, como diria Silvio Gallo (1997, p. 117), "o saber está intimamente relacionado com o poder: conhecer é dominar" e, desse modo, conhecer a mente que pensa, como ela funciona, para a Educação, é algo extremamente desejável, e isso por dois motivos: se conhecer é dominar, se busca aumentar a eficiência daquilo que se domina; ainda, se conhecer é dominar, pode-se exercer de algum modo um controle sobre o que se domina; assim, ao produzir e conhecer a mente, o pensamento e sua estrutura, pode-se exercer sobre esse pensamento um poder capaz de limitá-lo ou reencaminhá-lo para dado direcionamento.

Primeiro, para ensinar significativamente, é necessário conhecer o que o aluno já sabe, embora o saber pertença à estrutura cognitiva do sujeito e seja de natureza idiossincrática. Isso significa que não é um processo simples avaliar o que o sujeito sabe para em seguida agir de acordo. No entanto, é possível encontrar vestígios dos conhecimentos existentes na estrutura cognitiva do sujeito que aprende (Documento 63, p. 199).

No que tange à Educação Química, está claro que tais noções e vontade de saber sobre o pensamento também estão em sua organização. Dadas algumas qualidades evidenciadas acerca do conhecimento químico (abstrato, numenal, teórico, conceitual, etc.), conhecer, dominar e se apropriar dos modos como esse pensamento sobre ele funciona aparece na análise, sistematicamente, como um modo de potencializar sua ação e produzir um entendimento químico objetivado e mais direto. Requer-se nesse discurso quase que uma materialização do imaterial para que se compreendam os aspectos abstratos da ciência Química e, mais ainda, para que seja possível articular tal abstração com o nível fenomenológico e com as experiências vividas a cada dia. É assim que, nos documentos da QNEsc, em relação a um espaço de diferenciação, essas questões próprias ao funcionamento da mente se coordenarão na Educação Química, problematizando questões do tipo: como não trazer os aportes que conhecem como a mente funciona para a produção dos saberes e dos conhecimentos escolares de Química? Como compreender a relação entre o numenal e fenomenológico próprios à Química? Das várias questões possíveis, se evidencia que, em todas elas, encaminha-se uma ordem nesse discurso que não autoriza a qualquer proposta se encaixar no campo da Educação Química se ela não assumir a existência de uma estrutura mental, centrada na cognição. Tal estrutura organiza e dá condições à produção dos saberes e conhecimentos da Química na escola, pois se assume que "é uma construção única, própria de cada um deles [sujeitos do processo de aprendizagem]" (Documento 85, p. 5).

Em termos dos aportes que balizam tais ideias, notamos a forte proeminência de teorizações de nível cognitivo na Educação Química, particularmente aquelas direcionadas 
à aprendizagem. É nesse sentido que serão imensamente recorrentes e articuladoras da grande maioria dos processos analisados duas propostas: a da aprendizagem significativa e a do posicionamento sócio-histórico. Embora fundamentalmente distintas em suas ideias iniciais, nossa análise evidenciou que elas são sistematicamente apropriadas pela comunidade da Educação Química, que faz um uso hibridizado (Lopes, 2005) delas:

(...) os alunos chegam às salas de aula com ideias pré-concebidas sobre vários fenômenos e conceitos químicos desenvolvidos nas inúmeras situações que se defrontam em suas vidas. Para os alunos, suas concepções prévias ou alternativas fazem sentido e, por esse motivo são, muitas vezes, tão resistentes a mudanças. Dessa forma, acreditamos que essas concepções poderiam determinar o desenvolvimento de atividades em sala de aula, num processo mediado, de forma a promover a evolução destas. Assim, a aprendizagem é entendida como reorganização, desenvolvimento ou evolução das concepções dos alunos, ou seja, como uma evolução conceitual (Documento 70, p. 24).

Vygotsky (1993) trata a aprendizagem como uma constante negociação de significados. Em muitos casos, percebemos que os estudantes já têm uma noção sobre solubilidade e que esse processo de "negociação" deveria continuar para que a aprendizagem se consolidasse (Documento 70, p. 30).

Analisar isso implica em não trazer aqui a discussão da correção ou apropriação do uso integrado de tais propostas, pois a questão fundamental da pesquisa está em tanto uma quanto outra proposta serem pautadas na cognição e tal centramento mobilizar as condições que modulam e organizam o discurso do campo da Educação Química. Essa dinâmica tem alguns efeitos, um dos quais se articula com outro tema na produção do enunciado sondado.

\section{Aluno como Desejo}

Todos os quatro temas da análise trazidos até aqui não poderiam ser mobilizados, tal qual evidenciamos atualmente, sem a presença de outro tema: o do aluno que emerge como desejo. Mas o que isso significa? Evidenciamos nas análises que, quando a Educação Química traz qualquer elemento de como trabalhar conceitos, conteúdos, estratégias ou outros, aparece uma vontade de formar na aula de Química um aluno que seja consciente, participativo, que leia o mundo de modo aberto, que tenha condições mentais de associar diferentes conceitos e, por meio da interação, qualificar tais conceitos juntamente com outros sujeitos.
Ao falar dos alunos na Educação Química, não se faz referência a um ser presente nessa disciplina que se corre atrás para modificar, mas que ela cria e não cansa de produzir uma projeção, uma vez que este é seu objeto objetivado, o efeito de seu saber. Sempre se busca algo futuro aos alunos, como "criar o hábito e a atitude de encarar a aprendizagem como um problema, para o qual deve-se encontrar alternativas plausíveis e adequadas" (Documento 104, p.17).

O sujeito-aluno da Educação Química (e talvez de outros campos) é um ser que se objetiva participativo, ativo, com argumentos, interessado, dinâmico, etc. É desse modo que várias dinâmicas, estratégias, conteúdos, lógicas de pensamento e conhecimento de como o próprio pensamento é operado são postos em ação para dar conta de buscar esse aluno-objetivado, esse aluno-desejado. É assim que as práticas desse discurso proporão, por exemplo, que se proporcione aos estudantes um modo de compreender a importância da Química "de forma a conscientizá-los sobre a necessidade de uso correto dos agrotóxicos, e também favorecer o seu desenvolvimento intelectual, despertando-lhes espírito crítico, para que, dessa forma, possam interferir nos seus cotidianos" (Documento 56 p. 31).

Com esses elementos, verificamos, a todo o momento, que, ao se falar dos alunos, fala-se de uma função subjetiva no nível de sua virtualidade, de vir a ser. Não se fala ou se pratica aquele aluno que se tem, mas aquele que se deseja formar continuamente. Tais elementos, articulados aos demais temas apontados, modulam e permitem organizar a noção da prática de um discurso da área da Educação Química.

\section{Considerações finais: a Educação Química, a emergência de um discurso e contribuições à área}

Do ponto de vista analítico, visibilizamos que, sem haver prevalência de um ou outro tema construído na análise, eles se articulam e se interpelam, requisitando-se mutuamente. É desse modo que, seguindo o caminho lógico construído até então, o chamamento de uma produção cidadã, a construção de um entendimento químico por meio de estratégias diversas, conteúdos pouco variáveis e a articulação desses conteúdos, estratégias e formação numa relação plural e interdisciplinar têm efeitos na produção do próprio sujeito que atuará no campo em que tais elementos ocorrem. É nesse sentido que as relações entre práticas e poderes requerem a acentuação de uma figura subjetiva ao longo da produção da Educação Química. Tal figura será centrada num sujeito-aluno e, particularmente, será dado destaque ao nível cognitivo desse sujeito aluno.

No momento de construirmos a teia discursiva que dará condições à existência do discurso da Educação Química, a partir das produções publicizadas na QNEsc, percebemos que esses cinco temas contribuem na produção de uma ordem 
discursiva. É preciso notar, então, que trazermos isso como um dos resultados da análise não implica em reafirmar elementos que seriam consensuais no campo investigado ou que apresentariam certos tipos de objetos comumente estudados, mas que, mais profundamente, tais elementos efetivamente moldam, organizam, limitam, regulam e produzem esse campo, assinalando o que faria parte e o que não faria parte dele. Isso nos possibilita indicar, na constituição do enunciado sondado, que o discurso da Educação Química, em seu nível de materialidade, função subjetiva, espaço correlato e complementar (Foucault, 2009) passará por um sujeito-aluno, seu nível cognitivo e mobilizará estratégias, lógicas, conteúdos e posicionamentos para produzi-lo e, assim, produzir o próprio campo. É nesse ponto que esse estudo se difere dos demais já apresentados e, assim, contribui em pensar nossa área de pesquisas.

Associado ao conjunto das produções do campo da Educação Química, este texto se coloca como um modo distinto de olhar para o que vem sendo produzido nessa área, seja por seu viés teórico, seja pelo próprio objeto de estudo. Muitos elementos colaboram com a constituição de um campo, mas, em estudos como este, tornamos visível o visibilizável, atuando na evidenciação da pluralidade das práticas e na negação de verdades a priori. Verdades e ordens são produzidas, sim, mas sempre localizadas em determinada complexidade e feixe de ações historicamente engendradas e não postas de início. Isso, por um lado, permite compreender a mobilidade e mutabilidade de um campo, constituindo áreas ao mesmo tempo em que estas cessam e se transformam e, por outro, marca um modo de negação às metanarrativas e valorização das contingências históricas. Nem sempre a área da Educação Química existiu, muito menos há garantias de sua perpetuação infinita. O que este estudo encaminha aponta que, na atualidade, podemos falar dela e de um discurso que a constitui a partir de elementos discursivos compartilhados e que marcam sua ordem.

Assim, entendemos que conhecer e sondar o enunciado do campo em análise, reconhecer a centralidade da figura subjetiva de um aluno que se deseja formar e cujo centro é seu nível cognitivo a partir do qual todas as práticas, estratégias, conceitos e lógicas são propostas e balizam as ações, é tanto problematizá-lo, quanto expandi-lo e pensá-lo a partir de elementos distintos de si, possibilitando-nos sermos mais donos do seu futuro e, assim, do nosso próprio, como diria Álvarez-Gallego (1994).

Por fim, após nos colocarmos na conjuntura de um momento festivo de celebração dos já passados 20 anos de publicações da QNEsc, pensamos ser pertinente seguir apresentando pesquisas que contribuam com as análises desse campo, de suas produções e ações com o objetivo de sempre qualificar os debates e movimentos seguintes e, nesse sentido, é com esse foco que compartilhamos nosso trabalho com a comunidade à qual pertencemos.

\section{Notas}

1. Em razão da noção de rarefação da função autor num discurso que se analisa, optou-se por operar com códigos referentes a cada documento utilizado originalmente na pesquisa. Entretanto, respeitando os direitos de propriedade intelectual, é possível acessar a referência completa de cada documento, a partir da tese de doutorado do primeiro autor.

2. Muitos desses pontos constam no famoso Relatório Delors, produzido pela Comissão Internacional de Educação da UNESCO. O texto completo pode ser acessado em: http:// unesdoc.unesco.org/images/0010/001095/109590por.pdf (acessado em 29/12/2016).

3. Apenas os documentos 107 e 154 colocaram em xeque a ordem de vigência dos conceitos químicos. Todavia, somente o primeiro marcou com ênfase sua posição. Sob o título de Por que não estudar entalpia no Ensino Médio, o texto mobilizou questionamentos profundos a esse conceito (extremamente estável atualmente).

4. Apenas os editoriais (e nem todos) se esquivaram de traçar uma estratégia metodológica ou, ainda, alguns artigos acerca dos conceitos químicos escritos por pesquisadores com formação preponderante na área da ciência química aplicada.

\section{Referências}

ÁVAREZ-GALLEGO, A. Enfoque arqueológico-genealógico: orientaciones metodologicas para la lectura de fuentes primarias. [arquivo de texto em mensagem pessoal] Mensagem recebida por: <bspastoriza@gmail.com>. em: 18 set. 2014.p.1-8.

Las ciencias sociales en Colombia: genealogías pedagógicas. Bogotá: IDEP, 2013.

BEJARANO, N. R.R.; CARVALHO, A. M. P. A Educação Química no Brasil: uma visão através das pesquisas e publicações da área. Educación Química, v. 11, n. 1, p. 160-167, 2000.

BRAIBANTE, M. E. F.; WOLLMANN, E. M. A influência do PIBID na formação dos acadêmicos de Química Licenciatura da UFSM. Química Nova na Escola, v. 34, n. 4, p. 167-172, 2012.

CAAMAÑO, A. Química Nova na Escola: su impacto en España y su relación con las revistas españolas Alambique y Educació Química EduQ. Química Nova na Escola, v. 37, n. esp. 2, p. 127-132, 2015.

CACHAPUZ, A. F. Química Nova na Escola: um caso de sucesso. Química Nova na Escola, v. 37, n. esp. 2, p. 121-126, 2015.

CACHAPUZ, A. F.; GIL-PEREZ, D.; CARVALHO, A.M.P.; VILCHES, A. A Necessária Renovação do Ensino das Ciências. São Paulo: Cortez, 2005.

CAREGNATO, R. C. A.; MUTTI, R. Pesquisa qualitativa: análise de discurso versus análise de conteúdo. Texto e Contexto Enfermagem, v. 15, n. 4, p. 679-684, 2006.

CASTRO, P. M.; FERREIRA, L. N. A. Representações sociais de calor por estudantes de graduação em Química. Química Nova na Escola, v. 37, n. esp. 1, p. 26-34, 2015. 
CIRINO, M. M.; SOUZA, A. R. O discurso de alunos do Ensino Médio a respeito da "camada de ozônio". Ciência \& Educação, v. 14, n. 1, p. 115-134, 2008.

DÍAZ, E. A filosofia de Michel Foucault. São Paulo: Editora Unesp, 2012.

FERREIRA, L. N. A.; QUEIROZ, S. L. Autoria no Ensino de Química: análise de textos escritos por alunos de graduação. Ciência \& Educação, v. 17, n. 3, p. 541-558, 2011.

FISCHER, R. Adolescência em discurso: mídia e produção de subjetividade. Porto Alegre: [s.n.], 1996. Tese (doutorado) Universidade Federal do Rio Grande do Sul. Faculdade de Educação. Programa de Pós-Graduação em Educação. 1996.

FOUCAULT, M. Microfísica do Poder. São Paulo: Graal, 2013. . A Ordem do Discurso. São Paulo: Edições Loyola, 2011.

A Arqueologia do Saber. Rio de Janeiro: Forense Universitária, 2009.

. Michel Foucault explica seu último livro. In: FOUCAULT, M. Arqueologia das ciências e história dos sistemas de pensamento. Rio de Janeiro: Forense Universitária, 2008. p. 145-152.

. História da Sexualidade 1: A vontade de saber. Rio de Janeiro: Edições Graal, 1988.

GALIAZZI, M. C.; MORAES, R. Análise Textual Discursiva: processo reconstrutivo de múltiplas faces. Ciência \& Educação, v. 12, n. 1, p. 117-128, 2006.

GALIAZZI, M. C.; RAMOS, M. G. Aprendentes do aprender: um exercício de Análise Textual Discursiva. Indagatio Didactica, v. 5, p. 868-883, 2013.

GALLO, S. Conhecimento, transversalidade e educação: para além da interdisciplinaridade. Revista de Ciências Sociais, v. 10, n. 21, p. 115-133, 1997.

KRASILCHIK, M. Reformas e realidade: o caso do ensino das ciências. São Paulo em Perspectiva, v. 14, n. 1, p. 85-93, 2000.

LOPES, A. C. Teorias pós-críticas, política e currículo. Educação, Sociedade e Culturas, v. 39, p. 7-23, 2013.

Políticas curriculares: continuidade ou mudança de rumos? Revista Brasileira de Educação, n. 26, p. 109-118, 2004.

. Tensões entre recontextualização e hibridismo nas políticas de currículo. In: XXVIII Reunião Anual da Associação Nacional de Pós-graduação e Pesquisa em Educação. Caxambu: ANPED, p. 1-15, 2005.

A disciplina química: currículo, epistemologia e história. Episteme, v. 3, n. 5, p. 119-142, 1998.

MACHADO, R. Por uma genealogia do poder. In: FOUCAULT, M. Microfísica do Poder. São Paulo: Graal, 2013. p. 7-34.

MARÍN-DÍAZ, D. Autoajuda e educação: uma genealogia das antropotécnicas contemporâneas. 2012. 491f. Tese (doutorado) - Programa de Pós Graduação em Educação, Faculdade de Educação,Universidade Federal do Rio Grande do Sul, Porto Alegre. 2012.

Infância: discussões contemporâneas, saber pedagógico e governamentalidade. 2009. 199f. Dissertação (mestrado) Programa de Pós Graduação em Educação, Faculdade de Educação, Universidade Federal do Rio Grande do Sul, Porto Alegre. 2009.
MARTINS, I. Quando o objeto de investigação é o texto: uma discussão sobre as contribuições da Análise Crítica do Discurso e da Análise Multimodal como referenciais para a pesquisa sobre livros didáticos de Ciências. In: NARDI, R. (org.). A pesquisa em Ensino de Ciências no Brasil: alguns recortes. São Paulo: Escrituras Editora, p. 53-94, 2007.

MORAES, R. Uma tempestade de luz: a compreensão possibilitada pela Análise Textual Discursiva. Ciência \& Educação, v. 9, n. 2, p. 191211, 2003.

MORAES, R.; GALIAZZI, M. C. Análise Textual Discursiva. Ijuí: UNIJUÍ, 2007.

MORTIMER, E. F. Dez Anos de Química Nova na Escola: a consolidação de um projeto da Divisão de Ensino da SBQ. Química Nova na Escola, v. 20, p. 3-10, 2004.

NARDI, R. A pesquisa em Ensino de Ciências no Brasil: alguns recortes. São Paulo: Escrituras, 2007.

NARDI, R.; ALMEIDA, M. J. P. M. Investigação em Ensino de Ciências no Brasil segundo pesquisadores da área: alguns fatores que lhe deram origem. Pró-Posições, v. 18, n. 1, p. 213-226, 2007.

PINHÃO, F.; MARTINS, I. A análise do discurso e a pesquisa em ensino de ciências no Brasil: um levantamento da produção em periódicos entre 1998 e 2008. In. Anais do VII Encontro Nacional de Pesquisa em Educação em Ciências (ENPEC), Florianópolis, 2008.

QNESC. Editorial. Química Nova na Escola, v. 37, n. esp. 2, p. 115, 2015.

. Editorial. Química Nova na Escola, v. 35, n. 4, p. 227, 2013.

Editorial. Química Nova na Escola, v. 30, p. 1, 2008

Editorial. Química Nova na Escola, v. 1, p. 1, 1995.

RAMOS, M. G.; MASSENA, E. P.; MARQUES, C. A. Química Nova na Escola - 20 anos: um patrimônio dos educadores químicos. Química Nova na Escola, v. 37, n. esp. 2, p. 116-120, 2015.

SANTOS, G. R.; QUEIROZ, S. L. Leitura e interpretação de artigos científicos por alunos de graduação em química. Ciência \& Educação, v. 13, n. 2, p. 193-209, 2007.

SANTOS, K.; NETO, J. M. M.; SOUZA, P. A. A. Química e educação ambiental: uma experiência no Ensino Superior. Química Nova na Escola, v. 36, n. 2, p. 119-125, 2014.

SANTOS, W. L. P.; PORTO, P. A. A pesquisa em Ensino de Química como área estratégica para o desenvolvimento da Química. Química Nova, v. 36, n. 10, p. 1570-1576, 2013.

SANTOS, W. L. P.; SCHNETZLER, R. P. Educação em Química: compromisso com a cidadania. Ijuí: UNIJUí, 2014.

SCHNETZLER, R. P. A pesquisa em Ensino de Química no Brasil: conquistas e perspectivas. Química Nova, v. 25, supl. 1, p. 14-24, 2002.

SEPULVEDA, C.; EL-HANI, C. N. Apropriação do discurso científico por alunos protestantes de Biologia: uma análise à luz da teoria da linguagem de Bakhtin. Investigações em Ensino de Ciências, v. 1, n. 1, p. 29-51, 2006.

VEIGA-NETO, A. A ordem das diciplinas. Porto Alegre: [s.n.], 1996. 322p. Tese de Doutorado. Programa de Pós-Graduação em Educação. Faculdade de Educação, Universidade Federal do Rio Grande do Sul - UFRGS. 1996 


\section{Para saber mais}

ÁLVAREZ-GALLEGO, A. ...Y la escuela se hizo necesaria... En busca de un sentido actual de la escuela. Bogotá: Cooperativa Editorial Magisterio, 1994.
VEIGA-NETO, A. Foucault e a Educação. Belo Horizonte: Autêntica, 2007.

PASTORIZA, B. S.; DEL PINO, J. C. Para Falar de disciplina, corpos e conhecimentos entre os muros da escola. Revista Eletrônica de Educação, v. 9, n. 1, p. 301-317, 2015. 